\section{Commentary: octreotide and hypertrophic pulmonary osteoarthropathy}

\author{
R T Penson, R M Rudd
}

Hypertrophic pulmonary osteoarthropathy (HPOA) typically presents with painful and swollen wrists or ankles. It is frequently associated with clubbing and occasionally with gynaecomastia. Still more unusually, myxoedematous changes may occur in the face and ears. The osteoarthropathy is due to periostitis which leads to loosely woven subperiosteal new bone formation. This is seen radiographically as linear calcification outside the cortex of the distal diaphysis of the tibia, ulna and radius, sometimes with appearances described as "onion skin" or "candle wax".

HPOA has been reported to occur in up to $12 \%$ of bronchial carcinomas, ${ }^{1}$ which are responsible for $90 \%$ of the cases, and occurs particularly in squamous cell carcinomas. However, HPOA has been described with virtually every cause of clubbing. The chief differential diagnosis is thyroid acropachy which is typically painless and involves more distal long bones. Very rarely, vinyl chloride may cause acroosteolysis and mimic the condition.

The condition has been successfully treated by vagotomy and by interruption of intercostal nerves, suggesting a neurogenic origin. ${ }^{23}$ In the past it was common practice to sever the branches of the vagus around the hilum when cancers were found to be unresectable. ${ }^{2}$ Surgery and radiotherapy to the primary tumour may relieve the symptoms and, if relief occurs, it is usually rapid. Radiotherapy to the painful areas may also be effective. Persistent symptoms may often be relieved by non-steroidal anti-inflammatory agents. Steroids and low dose colchicine have also been advocated. In the presence of gynaecomastia associated with nonsmall cell carcinomas secreting human chorionic gonadotrophin or human placental lactogen the anti-oestrogen agent tamoxifen or local radiotherapy may be effective in relieving the discomfort.

The pathogenesis of HPOA remains uncertain. Although a common factor appears to be local hyperaemia, no specific endocrine, peptide or cytokine mediator has been consistently linked with the condition. Raised levels of hormones such as oestrogen have been blamed but clubbing was not seen as a con- sequence of treatment with stilboestrol for prostate cancer. Reduction of the metabolism of an unidentified vasoactive substance by pulmonary shunting seems unlikely to be the sole explanation despite a dog model demonstrating that HPOA can be induced by artificial creation of a shunt.

Acromegaly may occur with bronchial carcinoid associated with increased production of tumour growth hormone. HPOA has obvious similarities to acromegaly and has also been described in association with bronchial carcinoid. ${ }^{4} \mathrm{~A}$ similar syndrome has been described with adenocarcinoma, ${ }^{5}$ large cell carcinoma, ${ }^{6}$ and squamous cell carcinoma. ${ }^{7}$ In the latter case intense symmetrical uptake with ${ }^{99 \mathrm{~m}} \mathrm{Tc}$ hydroxymethanine diphosphonate was demonstrated in the distal portions of the long bones accompanied by markedly raised levels of growth hormone in the serum. After treatment with chemotherapy and radiotherapy for the cancer, the arthralgia disappeared and scintigraphic findings and serum growth hormone levels improved, suggesting that ectopic production of growth hormone in the pulmonary tumour may have been the cause of the osteoarthropathy.

In this issue of Thorax Johnson et al report an interesting phenomenon - namely, the response of painful HPOA to octreotide, a synthetic analogue of somatostatin, the hormone inhibitor or "endocrine arsenic". Although we are not told of the response of the primary tumour to radiotherapy, the response of the pain to octreotide and to its reinstitution provides compelling evidence for an effect of the drug. It is interesting that there was no change in the gynaecomastia, perhaps supporting the hypothesis of an effect through growth hormone.

The role of octreotide is well established in controlling the growth and secretions from pituitary adenomas, particularly in acromegaly, and the neuroendocrine tumours. It is commonly used in palliative care to control the vomiting associated with intra-abdominal malignancies by reducing the volume of secretions. It is used in bowel obstruction although this is not, as yet, supported by controlled trials. The non-opioid analgesic effect of octreotide by intrathecal infusion has been reported in an uncontrolled series of six patients, ${ }^{9}$ reproducing earlier work using intrathecal somatostatin, ${ }^{10}$ and this use is supported by growing evidence for the inhibitory effects of octreotide on nociceptive neurones. However, in a randomised, single blind, crossover study $200 \mu \mathrm{g}$ octreotide by subcutaneous bolus was found to be no better than placebo in nine out of 10 patients in the relief of advanced cancer pain. ${ }^{11}$

Disparate hypotheses abound regarding the aetiology of HPOA. As yet there is little information about the value, if any, of bis- 
phosphonates which are being used increasingly for the relief of pain from bone metastases. ${ }^{12}$ Perhaps most promise is held out by research into angiogenesis and its role in malignancy and metastasis. This field of research, although in its infancy, is exciting and may provide more aetiological information and possibly new treatments for HPOA. ${ }^{13}$

1 Green N, Kurohara SS, George SW, et al. The biologic behaviour of lung cancer according to histological type. Radiol Clin Biol 1972;41:160-70.

2 Flavell G. Reversal of pulmonary osteoarthropathy by vagotomy. Lancet 1956;i:260.

3 Holman CW. Osteoarthropathy in lung cancer: disappearance after section of intercostal nerves. 7 Thorac appearance after section of

4 Bradford R, Griffiths MH, Goldstraw P. Hypertrophic pulmonary osteoarthropathy in association with a bronchial carcinoid. Br $\mathcal{F}$ Dis Chest 1984;78:275-81.
5 Steiner H, Dahlback OV, Caldenstrom J. Ectopic growth hormone production and osteoarthropathy in carcinom of the bronchus. Lancet 1968;i:783-5.

6 Namori H, Kobayashi R, Kubo A, Morinaga S, Shintani Y, Salo T. Lung cancer containing growth hormone-releasing hormone associated with hypertrophic osteoarthropathy. Scand F Thorac Cardiovasc Surg 1994;28:149-52.

7 Uchisako H, Suga K, Tanaka N, et al. Bone scintigraphy in growth hormone-secreting pulmonary cancer and hypertrophic osteoarthropathy. F Nucl Med 1995;36:822-5.

8 Johnson SA, Spiller PA, Faull CM. Treatment of resistant pain in hypertrophic pulmonary osteoarthropathy with subcutaneous octreotide. Thorax 1997;52:298-9.

9 Penn RD, Paice JA, Kronin JS. Octreotide: a potent new non-opiate analgesic for intrathecal administration. Pain 1992;49:13-19.

10 Chrubasik J, Meynadier J, Blond S, et al. Somatostatin, a potent analgesic. Lancet 1984;ii: 1208-9.

11 De Conno F, Saita L, Ripamonti C, Ventafridda V. Subcutaneous octreotide in the treatment of pain in advanced cancer patients. F Pain Symptom Manage 1994;9:34-8.

12 Berenson J, et al. Efficacy of pamidronate in reducing skeletal events in patients with advanced multiple myeloma. $N$ Engl F Med 1996;8:488-93.

13 Folkman J. Tumour angiogenesis. In: Mendelsohn J, Howley PM, Israel MA, Liotta LA, eds. The molecular basis of cancer. New York: W B Saunders, 1995.
Treatment of resistant pain in hypertrophic pulmonary osteoarthropathy with subcutaneous octreotide

\author{
S A Johnson, P A Spiller, C M Faull
}

\begin{abstract}
Pain in hypertrophic pulmonary osteoarthropathy (HPOA) due to periostitis and arthropathy can be a particularly disabling symptom, and resistant to a wide variety of treatments. The effectiveness of subcutaneous octreotide in relieving this pain in a patient with HPOA is reported.

(Thorax 1997;52:298-299)
\end{abstract}

Keywords: hypertrophic pulmonary osteoarthropathy, octreotide.

The syndrome of secondary hypertrophic pulmonary osteoarthropathy (HPOA) is most commonly associated with a peripheral bronchogenic carcinoma, but also occasionally with pleural mesotheliomas. It consists of a symmetrical periostitis affecting the long bones of the extremities, an arthropathy of the wrists, ankles and knees, and gross finger clubbing. Gynaecomastia is seen in approximately $10 \%$ of cases.

The pathogenesis remains uncertain. The variety of clinical features and efficacy of different therapeutic procedures account for the various proposed theories. These include reflex vagal stimulation causing the release of vasoactive intestinal polypeptides resulting in increased blood flow to the extremities, ${ }^{1}$ peripheral impaction of megakaryocytes and platelet clumps in the fingers and toes resulting in the release of platelet-derived growth factor, ${ }^{2}$ a hormonal mechanism suggested by high plasma levels of growth hormone, ${ }^{3}$ and increased excretion of oestrogen ${ }^{4}$ found in some patients with HPOA.

The predominant symptom is pain due to the periostitis. First line management is aimed at treating the primary tumour but, in resistant cases when the pain can be persistent and very disabling, other therapies have been found to be effective - for example, vagotomy ${ }^{1}$ and nonsteroidal anti-inflammatory drugs (NSAIDs).

Octreotide, a synthetic analogue of somatostatin, is well recognised as an inhibitor of growth hormone and gastroenteropancreatic peptide secretion. It has recently been used successfully in the management of chronic cancer pain. ${ }^{5}$ Here we report its success in providing relief for a patient with uncontrolled pain due to HPOA.

\section{Case report}

Five months after bronchoscopic diagnosis of a poorly differentiated squamous cell carcinoma of the bronchus a 54 year old man developed painful lower legs and knees, which resulted in severe difficulty in walking, and painful gynaecomastia. Radiographs of his lower limbs confirmed the typical radiological appearances of the subperiosteal new bone formation of HPOA.

Symptoms persisted despite radiotherapy to the primary tumour, opiates, and various NSAIDs. Treatment with dexamethasone ( $4 \mathrm{mg} /$ day), amitriptyline, sodium valproate, and a trial lumbar sympathectomy with $0.5 \%$ bupivacaine all produced no benefit.

In view of the painful gynaecomastia and therefore possible hormonal aetiology of the HPOA, a trial of subcutaneous octreotide was administered at a dose of $100 \mu \mathrm{g}$ twice daily. This resulted in complete relief of his pain over the following few days and, with physiotherapy,
Received 22 May 1996

Accepted for publication

18 July 1996 
marked improvement in his walking. There was, however, no improvement in the pain or size of his gynaecomastia.

After one week he became reluctant to continue with twice daily injections and requested that the octreotide was stopped. Within 24 hours his symptoms had returned, prompting reintroduction of octreotide, this time $200 \mu \mathrm{g}$ by a 24 hour subcutaneous infusion to avoid the discomfort of repeated injections. He again became pain-free and mobile, sufficient to enable discharge home after only three days.

\section{Discussion}

Octreotide is known to have a wide clinical application in the management of many endocrine disorders. Its effect on nociceptive pain pathways is as yet unclear, and limited clinical experience means its role as an analgesic agent is unsure. It has been suggested, however, that it may become important as an adjunct or in particular pain syndromes. ${ }^{5}$
In the case reported it provided complete pain relief in a difficult pain problem. The presence of the HPOA-associated gynaecomastia raised the possibility of a hormonal aetiology for the clinical picture and perhaps suggests that the symptomatic response to octreotide was because of a direct effect on the underlying disease mechanisms rather than a primary analgesic effect.

Octreotide may be a useful analgesic for treating the pain of HPOA when more conventional treatment has failed. It needs further evaluation, however, to determine its mechanism of action and thus enable identification of patients who are most likely to benefit.

1 Yacoub $M$. Cervical vagotomy for pulmonary osteoarthropathy. Br 7 Dis Chest 1965;59:28-31.

2 Dickinson CJ. The aetiology of clubbing and hypertrophic osteoarthropathy. Eur 7 Clin Invest 1993;23:330-8.

3 Gosney MA, Gosney JR, Lye M. Plasma growth hormone and digital clubbing in carcinoma of the bronchus. Thorax 1990;45:545-7.

4 Ginsberg J, Brown JB. Increased oestrogen excretion in HPOA. Lancet 1961;ii: 1274

5 De Conno F, Saita L, Ripamonti C, Ventafridda V. Subcutaneous octreotide in the treatment of pain in advanced cancer patients. F Pain Symptom Manage 1994;9:34-8.

\section{Unilateral}

hypertranslucency of the left hemithorax due to aneurysm of the thoracic aorta

\footnotetext{
Pulmonary

Department

S Loukides

K Katsoulis

P Panagou

T Papavergos
}

Nuclear Medicine

Department

K Bougas

Computed

Tomography

Department

S Lachanis

401 Army General

Hospital, Athens,

Greece

Correspondence to:

Dr S Loukides, Department

of Thoracic Medicine,

National Heart and Lung

Institute, London SW3 6LY,

UK.

Received 4 December 1995

Returned to authors

27 February 1996

Revised version received

29 April 1996

Accepted for publication

6 June 1996

This case was reported as a

Poster at the 4th Annual

Meeting of the European

Respiratory Society,

Barcelona, 16-20 September

1995
S Loukides, S Lachanis, K Katsoulis,
P Panagou, K Bougas, T Papavergos

\begin{abstract}
A 19 year old man presented with a six months history of dyspnoea on exertion. Chest radiographs, isotopic lung scans, and computed tomographic scans of the chest showed unilateral translucency of the left lung, absence of ventilation and perfusion in the same lung, and a $3.5 \mathrm{~cm}$ aneurysm of the descending thoracic aorta which compressed the left mainstem bronchus.
\end{abstract}

(Thorax 1997;52:299-300)

Keywords: dyspnoea, aortic aneurysm, unilateral hypertranslucency.

There have been several recent reports of a nosological entity described as "unilateral pulmonary emphysema" or abnormal transradiancy of one lung, first reported by Swyer and James in $1953^{1}$ and McLeod in $1954 .^{2}$ Apart from these syndromes, increased radiolucency of one hemithorax occurs in many other conditions such as compensatory em- physema, obstructive emphysema, bullae and cyst and pulmonary vascular obstruction. The most common causes are foreign body inhalation and congenital lobar emphysema in children and bronchial tumours in adults. ${ }^{3}$

Aneurysms of the thoracic aorta may cause obstructive hypertranslucency due to extrinsic compression of the tracheobronchial tree.

\section{Case report}

A 19 year old man presented with a six months history of dyspnoea on exertion. Two years prior to his admission he had a traffic accident which caused him a chest trauma without complications at that time. The patient had never smoked. Physical examination showed a small reduction of breath sounds in the left hemithorax. The results of laboratory blood tests were normal.

A posteroanterior chest radiograph (fig 1) revealed unilateral translucency of the left lung, and air trapping was found on inspirationexpiration chest radiographs. Lung function

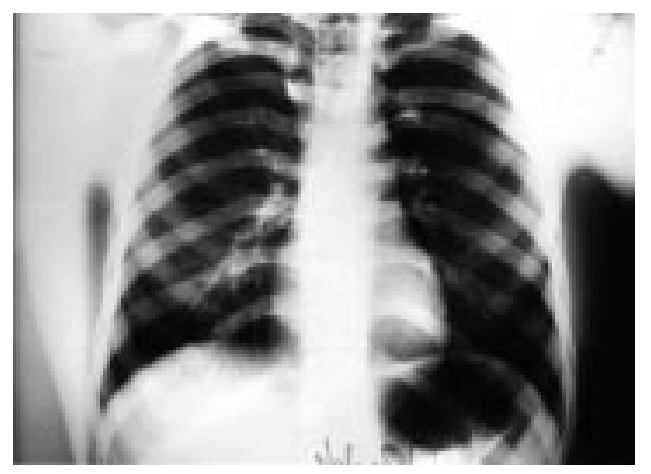

Figure 1 Posteroanterior chest radiograph showing unilateral translucency of the left lung. 


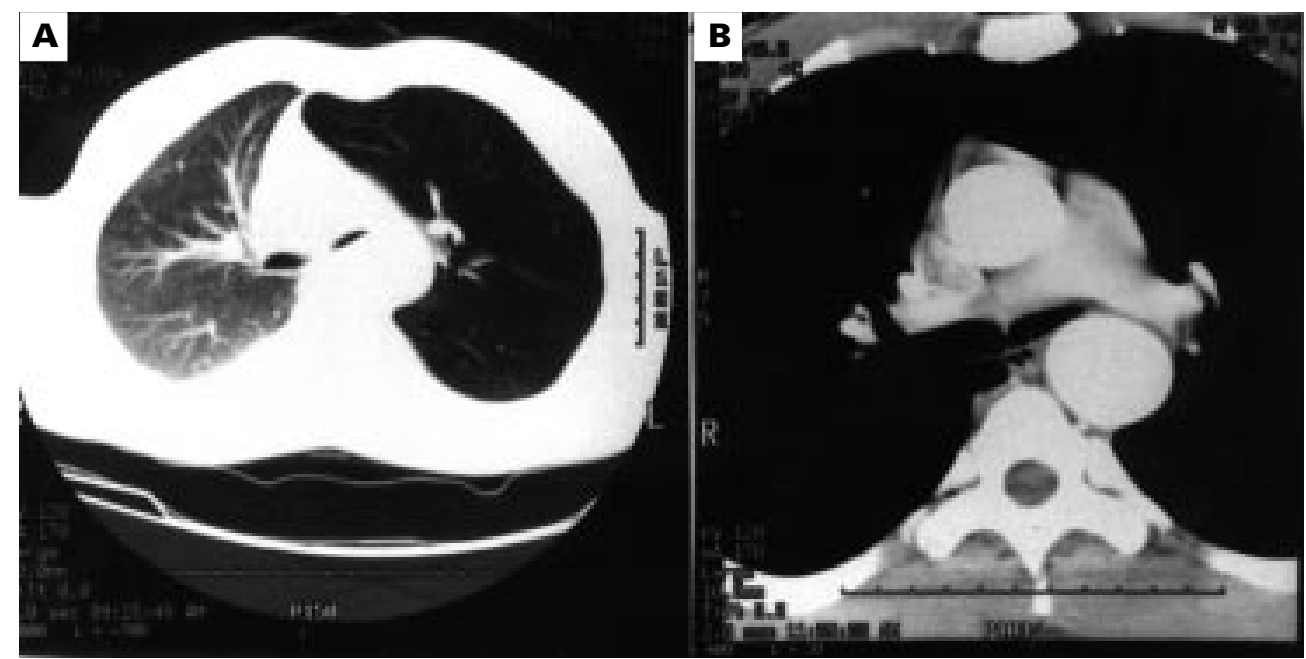

Figure 2 Computed tomographic scan of the chest showing (A) striking hypertranslucency of the left lung associated with an increase in volume and decrease in the diameter of the pulmonary vessels and (B) compression of the left mainstem bronchus by a $3.5 \mathrm{~cm}$ aneurysm of the descending aorta.

studies showed an obstructive pattern with forced expiratory volume in one second $\left(\mathrm{FEV}_{1}\right)$ 1.361 (32\% predicted), forced ventilatory capacity (FVC) 1.911 (38\% predicted), forced mid expiratory flow $\left(\mathrm{FEF}_{25-75}\right) 0.471$ (23\% predicted), residual volume (RV) 2581 (161\% predicted), and total lung capacity (TLC) 6.321 ( $99 \%$ predicted). There was no response to an inhaled bronchodilator. The carbon monoxide lung transfer factor (TLCO) was $50 \%$ predicted, arterial oxygen tension $\left(\mathrm{PaO}_{2}\right)$ was $8.5 \mathrm{kPa}$, arterial carbon dioxide tension $\left(\mathrm{PaCO}_{2}\right) 4.7 \mathrm{kPa}$, and $\mathrm{pH} 7.47$.

Ventilation-perfusion isotopic lung scans showed absence of ventilation and perfusion of the left lung. Fibreoptic bronchoscopic examination revealed an extrinsic compression of the left main bronchus. The rest of the bronchial tree was normal. A computed tomographic (CT) scan of the chest (fig 2) showed that there was striking hypertranslucency of the left lung associated with an increase in volume and decrease in the diameter of the pulmonary vessels, possibly related to compensatory vasoconstriction (fig 2A). The left mainstem bronchus was smoothly compressed by a $3.5 \mathrm{~cm}$ aneurysm of the descending aorta (fig 2B).

The patient was operated on successfully. An aneurysmatic dilation $(3.5 \mathrm{~cm} \times 3 \mathrm{~cm})$ was found $2 \mathrm{~cm}$ beyond the origin of the left subclavian artery. At thoracotomy a complete tear of the intima and media of the aorta was found, the continuity of the vessel being maintained by adventitial coasts only. After removal of the aneurysm the continuity of the aorta was established by a prosthetic graft. His clinical condition improved and lung function tests, blood gas tensions and chest radiograph became normal.

\section{Discussion}

We have described a case of unilateral hypertranslucency of the left lung caused by an aneurysm of the thoracic aorta. Aortic an- eurysms may be classified as arteriosclerotic, syphilitic, traumatic, dissecting, post-stenotic, and mycotic. The cause of our patient's aneurysm was probably post-traumatic as he had had a chest trauma two years prior to his admission. Serological tests for syphilis were negative.

Aneurysms of the thoracic aorta may be found by chance on chest radiographs in an otherwise asymptomatic patient, or may present as pain from aortitis, erosion of the sternum or vertebral column and compression of the spinal nerves, or as symptoms arising from compression of adjacent structures. ${ }^{4}$ Respiratory symptoms result from compression of the tracheobronchial tree. In some cases compression may cause severe respiratory failure and indicate the need for emergency surgery. ${ }^{5}$ In most patients, as in our case, dyspnoea alone without chest pain is the presenting respiratory symptom and its severity varies according to the size and location of the dilatation of the aneurysm. ${ }^{6}$ CT scanning and bronchoscopy clearly show the level of the compression. ${ }^{7}$ Surgery is indicated when the patient is symptomatic as a result of the aneurysm. Aneurysms of the descending aorta should be included in the differential diagnosis in patients with unilateral hypertranslucency and an appropriate history. In patients with such a finding a bronchial biopsy should not be attempted before CT scans are obtained.

1 Swyer PR, James GCW. A case of unilateral pulmonary emphysema. Thorax 1953;8:133-5.

2 McLeod WM. Abnormal transradiancy of one lung. Thorax 1954;9:147-51

3 McKenzie S, Allison DJ, Singh M, Godfrey S. Unilateral hyperlucent lung: the case for investigation. Thorax 1980 35:745-50.

4 Phillips CD, Smith EEJ, Millord FJC. Positional dyspnoea due to aneurysm of the thoracic aorta. Eur Respir $\mathcal{F} 1994$ 7:412-4.

5 Bevelaqua F, Salazar J, Haas F, Axen K, Levin N. Aortic arch anomaly presenting as exercise induced asthma. $A m$ Rev Respir Dis 1989;140:805-8.

6 Varkey B, Tristani F. Compression of pulmonary artery and bronchus by descending thoracic aortic aneurysm. $A m \mathcal{F}$ Cardiol 1974;34:610-4.

7 Bron A, Mensen EAM, Dijkman JH, Hugsmans HA, Aaliburs R. Dyspnoea persisting after surgery for a vascular ring. Eur Respir f 1994;7:2257-9. 